\title{
Cloud Computing Applications in Banking Sector: A literature Survey
}

\author{
P.Swathi ${ }^{1}$, K. Gayathri ${ }^{2}$, T.Sandhya ${ }^{3}$ \\ Dept. of Computer Science, S.V.University, Tirupathi, AP,INDIA. \\ Dept. of Computer Science, Vignana Bharathi Institute of Technology, Proddatur, AP, INDIA. \\ Dept. of Computer Science, S.V.University, Tirupathi, AP, INDIA.
}

\begin{abstract}
This Cloud computing is internet-based computing, anywhere shared resources, software, and information are provided to computers and other devices on demand. Business services will be the largest market for cloud services spending with a gradual evolution from on-premise to cloud-based services especially for banking sector. Banks are expected to enter the cloud computing field cautiously, with no single cloud services delivery model being a silver bullet for best meeting their demanding business needs. But before stirring to the cloud, banks must consider issues around data confidentiality, security, regulatory compliance, interoperability of standards, and quality of services. The key to success lies in selecting the exact cloud services model to match business needs.
\end{abstract}

Keywords: Cloud, banking, applications

\section{Introduction}

Cloud computing is a model for triggering ubiquitous, convenient, on demand network access to a shared pool of configurable computing assets (e.g., networks, servers, storage, applications, and services) that can be quickly provisioned and released with minimal management effort or service provider interaction.The cloud offers a host of opportunity for banks to build a more stretchy, quick and customer-centric business model that can drive gainful growth. "Cloud computing can increase the competitiveness of smaller banks". Small banks, which do not have resources to spare to invest in expensive servers and other infrastructure, can advantage from the use of cloud technology.

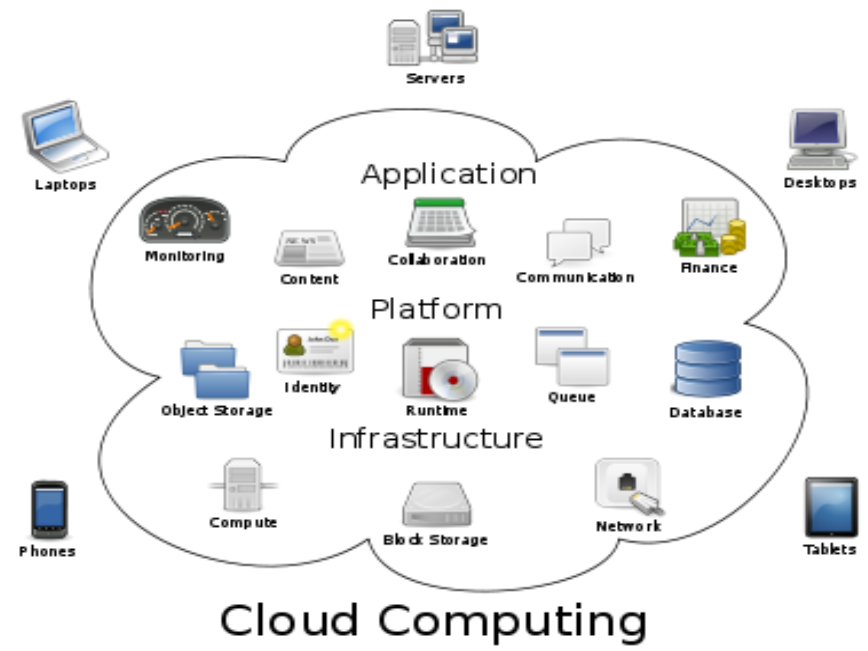

Fig:1 Cloud Computing Process

\subsection{The cloud model is composed of five essential characteristics}

1.1.1 On demand self-service: A consumer can unilaterally provision computing capability such as server time and network storage, as needed automatically without requiring human communication with both service provider.

1.1.2 Broad network access: Capabilities are available over the network and accessed through standard mechanisms that promote use by heterogeneous thin or thick client platforms

1.1.3 Resource Pooling: The provider's computing resources are mutual to serve multiple consumers using a multitenant model, with different physical and practical resources animatedly assigned and reassigned according to consumer order. There is a sense of location autonomy in that the customer generally has no manage or 
knowledge over the precise location of the provide resources but may be able to state location at a higher level of abstraction .Examples of resources include storage, processing, memory, and network bandwidth.

1.1.4 Rapid Elasticity: Capabilities can be elastically provisioned and unconfined in some cases automatically, to scale rapidly outward and inward appropriate with demand. To the consumer, the capabilities available for provisioning often appear to be unrestricted and can be appropriated in any quantity at any time.

1.1.5 Measured Service:Cloud systems frequently controls and optimize resource use by leveraging a metering capabilitylat some level of abstraction appropriate to the type of service . Resource usage can be monitored, controlled, and reported providing transparency for both the provider and consumer of the utilized service [1].

\subsection{Before cloud technology used}

Banks have long been built on very big amount of data. But as "big data" gets even larger, legacy storage systems are growing increasingly inefficient and even obsolete, according to industry experts. Financial services firms now recognize the emergent need for quick access to centralized data, and they are not content to propagate the traditional model of storing data in multiple silos. Customers are also asking for one huge, big system where all the data they could ever want is on that system. "The biggest problems banks have is that data, in many cases, is soiled and in disparate locations. The magic is being able to bring that together and allow that data to become useful for them." To improve security, efficiency, worthy cloud provider encrypts data in storage as well as in transit. "They've also made significant investments in identity and access management".

\subsection{After the cloud technology}

The surfacing of cloud-based banking promises to affect banks big and small. Banks are predictable to spend almost $\$ 180$ billion on IT for 2015 year. For the moment cloud-based services make up a small fraction of this amount, but by some estimates spending by financial-services firms on the cloud will total \$26 billion in 2015. This increase should lesser barriers to entry for newcomers, which can rent modern IT infrastructure at monthly fees of less than $\$ 10,000$ rather than having to invest tens of millions of dollars upfront to build their own secure data centre's. Small firms, without legacy computer systems to constrain them, are the fastest movers. Its employee type document, run spreadsheets and read e-mails in the cloud. It's banking software, which keeps track of clients, payments and loans, runs on a cloud-computing platform also [1].

\subsection{Why the banks need the cloud computing technology}

For banks, today's shifting business realities and growing markets represent tremendous growth potential. The financial wealth in emerging markets will reach USD14 trillion by 2015 and 2.7 billion adults in developing nations lack access to financial services. Global financial assets are set to triple by 2020 to USD37 trillion. Cloud computing can plays a significant role in a bank's efforts to re-invent its business and operating models. In technical terms, a cloud computing platform automatically assembles, connects, configures and reconfigures virtualized technology resources to meet business goals. In business terms, it removes constraints around where physical IT resources are located or what specific technologies are employed, which makes it possible to deploy business services feasible. Cloud computing can offer benefits for many sectors like banks, as shown in Table 1.

Table: Cloud Areas

\begin{tabular}{|l|l|}
\hline Area & Sample benefit \\
\hline Analytics & Integrating customer data across banking platforms to enable near real-time insights. \\
\hline Business services & $\begin{array}{l}\text { Extending and incorporating third-party services to extend the banking ecosystem to support } \\
\text { customer's everydaybuying and paying needs. }\end{array}$ \\
\hline Collaboration & $\begin{array}{l}\text { Enabling employees across distributed branches to access trading and banking systems } \\
\text { through a security-richcloud infrastructure. }\end{array}$ \\
\hline Desktops and devices & $\begin{array}{l}\text { Deploying a private cloud to centralize management of desktops allows for greater remote } \\
\text { flexibility without sacrificingcontrol, while enabling banking employees to access the } \\
\text { required applications and data. }\end{array}$ \\
\hline Development and testing & $\begin{array}{l}\text { Enabling a bank's development teams to quickly and easily create virtual environments thus } \\
\text { increasing the agility ofdevelopment and testing. }\end{array}$ \\
\hline Infrastructure compute & $\begin{array}{l}\text { Allowing capacity to be allocated, expanded and reallocated efficiently gives banks } \\
\text { flexibility and agility while resolvingthe issues of complexity and cost increases related to } \\
\text { scaling up traditional network models to accommodatefuture growth. }\end{array}$ \\
\hline Infrastructure storage & $\begin{array}{l}\text { Providing scalable storage solutions to ensure that the real-time demands of today's trading } \\
\text { and analytics processesare maintainable. }\end{array}$ \\
\hline Managed backup & $\begin{array}{l}\text { Backing up a bank's critical business data to ensure that in the event of a disaster a bank can } \\
\text { bounce back rapidlyand easily }\end{array}$ \\
\hline Security & $\begin{array}{l}\text { Enforcing active security and endpoint management to ensure corporate governance and } \\
\text { banking IT policiesare maintained }\end{array}$ \\
\hline Industry applications & Enabling payment providers to standardize and modernize transaction processing \\
\hline
\end{tabular}

The benefits that cloud computing can offer acress various banking IT service areas 


\subsection{Advantages}

\section{Advantages Of Cloud Computing In Banking Sector}

\subsubsection{The cloud brings agility to banks}

Cloud computing enhances business agility where banks get the ability to react quickly to service requests not only from their internal IT staff but also to requests coming from external customers. This supports a faster and more efficient response to the needs of banking customers. Since the cloud is available on-demand, less infrastructure investments are required, saving initial set-up time. The Cloud enables faster time-to-market and greater flexibility for new products and services to be launched.

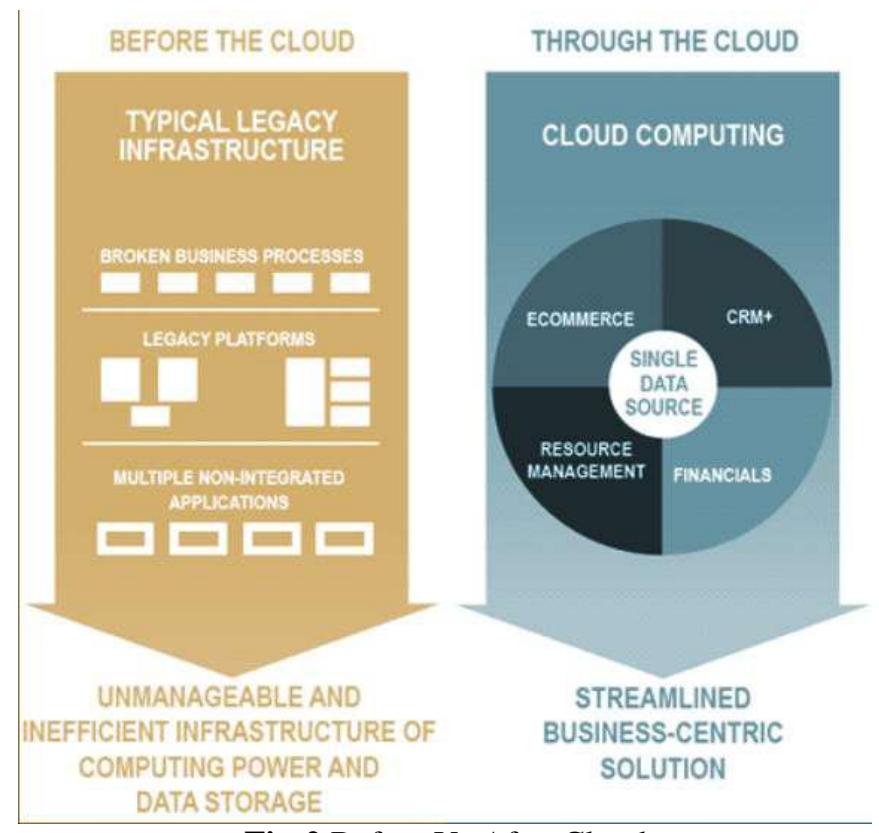

Fig:2 Before Vs After Cloud

\subsubsection{Ensuring greater customer centricity in a market where product differentiation is tough}

The customer is expecting more and complicated challenges from banking industry. Banks need to provide a more engaging experience and deliver customer-centric services to hold old customers and magnetize new ones. In today's environment, firms need to rebuild trust through improved transparency and enhanced service levels to its customers. An analytics solution offered through the Cloud will help banks to deploy a shared business intelligence and analytics environment rapidly at optimal costs and will provide a single consistent view of the business enabling better decision-making. In addition, Cloud services will help banks to increase speed and responsiveness in test and development environments. This would enable shorter time-tomarket and greater flexibility for new products and services.

2.1.3 Infrastructure SavingsWith the cloud-based virtualization of desktops, data centre, and local networks, banks can create savings from thecommodity portion of IT expenses, freeing up capital for business facing applications. The Cloud's integrated, standardized platforms allow for greater scalability across organizations of every size.

\subsubsection{Banks consider cloud computing to improve efficiency, cut costs}

Faced with increasing technology costs and under-utilized hardware, banks are increasingly looking at cloud computing as a means to improve efficiency and cut costs. Banks can scale up their operations with no adding to either of one costs, manpower hardware and software. Cloud computing is the delivery of computing as a service rather than a product, whereby shared resources, software, and information which provides to computers and other devices as a utility over a network .Since the hardware and software are available on require, the user need to pay for utilized and there is no need to invest in huge. Large banks often deploy a lot of capacity in-house and more than adequate hardware, which is not used optimum. But by means of cloud computing, they could scale up and decline costs. So, for such banks, it would make sense to switch a function such as treasury applications, if not entire core banking services to cloud [3].

\subsubsection{The various flavours of cloud computing:}

\subsubsection{Public clouds:}

Public clouds extend the data centre capabilities by enabling the provisioning of IT services from thirdparty providers over a network. The data and processing may be located anywhere in the world of infrastructure which is pooled with the cloud provider's or "tenants". 


\subsubsection{Private clouds:}

Private clouds are built which applies to virtualization inside a bank's own data hub. Because external "tenants" are not exposed to private clouds, banks tend to stare them as a more secure environment for customer data.

\subsubsection{Hybrid clouds:}

Hybrid clouds means which mix the public and private clouds together depending on the sensitivity of the data and applications in each process, business criticality and differentiation. Most banks will go behind a "hybrid" cloud strategy which can also be a cloud owned by and located within the bank, but operated by a third-party.

\subsection{Banks that are using cloud technology}

MANILA, Philippines-Philippine banks will be among the first in Southeast Asia that will be able to use "cloud" computing solutions in their operations, improving the industry's competitiveness in the region.

BBVA banks on Google cloud:

In January, 2012, BBVA announced its decision to migrate its entire 110,000-strong workforce to Google Apps-representing Google's biggest enterprise contract to date. The bank plans to use Google applications like Gmail, Chat, Calendar, Docs and Video Conferencing and other collaboration tools to "achieve a cultural change" across the 26 countries where BBVA currently does business. The decision to distribute BBVA's data across a public cloud managed by Google's data centre was driven - in part - by the increasing mobility of the bank's workforce. For example, much of the bank's computing needs have moved to smart phones, tablets, laptops and computers used outside the bank's walls. Deutsche Bank is set to complete the first phase of a major cloud computing overhaul aimed at improving internal application development. The German investment bank, which has a substantial presence in the City of London, has developed an Infrastructure as a Service (IaaS) development platform, due to go live this month.

\subsection{How Banks Can Adopt The Cloud Securely:}

In Ancient days people used to keep their money under the mattress, pots and some secret places because they doesn't know where to secure it. Later they came to know that it is not safe to hide them in such places so they started keeping their money in the banks for security and safe. Similarly, cloud services are developing along the lines that they will ultimately become the recognized safe repository for valuable data.

\subsubsection{Compliance through encryption:}

Financial services companies should use encryption to diminish the risk of revelation or alteration of sensitive information stored and transfer. This is the best method to maintain your information safe from hackers. From this, a secret pair of digital codes called 'keys' is used to encrypt the software. With this secret key, decrypting the software will be done. Encryption therefore protects your vital data against interfering eyes, despite of where it is stored. Others who attempt to get out of the company's protocols for data access will retrieve only scrambled information. Encryption needs to work faultlessly for business users and their customers, so they are able to rescue their information faultlessly. However, the problem arises. Who should actually own the keys?

\subsubsection{Keep the keys, rotate the keys, and destroy the keys:}

Financial services companies should use encryption to diminish the risk of revelation or alteration of sensitive information stored and transfer. This is the best method to maintain your information safe from hackers. From this, a secret pair of digital codes called 'keys' is used to encrypt the software. With this secret key, decrypting the software will be done. Encryption therefore protects your vital data against interfering eyes, despite of where it is stored. Others who attempt to get out of the company's protocols for data access will retrieve only scrambled information. Encryption needs to work faultlessly for business users and their customers, so they are able to rescue their information faultlessly. However, the problem arises. Who should actually own the keys?

\subsection{The future cloud in Banking}

\subsubsection{Customer relationships will be redefined}

Maintaining the relationship between the customers in cloud computing will show how it redefine and provide the banking services and products. By Cloud computing there is possibility to provide the services more convenient, more accessible, easier to use, and more personalized to the individual's needs and lifestyle. This is both a threat and an opportunity as it remains to be seen whether it is banks that lead this change-or, increasingly, non-banking entrants.

\subsubsection{Non-banking cloud-based competitors will keep up the pressure}

Rather than being technologically, innovative, the emerging generation of cloud-based, socially-driven money management tools are customer services and experience innovators. They will carry on to ramp up efforts to win customers not just from banks, between them too. There for Banks must,continue to respond to these competitive issues in order to avoid disintermediation-by investing in capabilities around social media, analytics, and targeted product and service bundling. 


\subsubsection{Emerging market banks will lead cloud-based innovation}

Budding market banks generally have less systems and infrastructure heritage than their counterparts in mature markets, making it easier for them to adopt cloud models. At the same time, banking modernism in emerging markets is being accelerated by earlier economic growth and individual social needs. Witness the success of M-PESA in Kenya and other emerging countries, and the provision of online and mobile market information for farmers in India and Bangladesh. For those emerging market banks too small to invest alone in a cloud-based core banking infrastructure, they may choose to form a consortium to leverage a shared cloud. In this case, they could collaborate to build and share a new core system that allows them to be more flexible and create more products for their customers. In a number of Latin American markets, the largest two or three banks might be able to invest millions of dollars on their infrastructure but they would be the exception. In Panama, for example, there are nearly 50 banks that have assets of fewer than $\$ 5$ million.

\subsubsection{Emerging markets: ATMs in the cloud}

For banks seeking to grow rapidly in emerging markets and reach unbanked customers, the time and cost of setting up distribution represent major hurdles. Opening a branch or installing a new ATM is costly and can take weeks together. So third-parties could offer cloud-based services that support rapid growth in a bank's distribution network and infrastructure. Examples might include telecom's using their network assets to offer ATMs or point-of sale terminals in a cloud. The cloud could help overseas correspondent banks conduct foreign transactions for smaller institutions in their home country

\section{Conclusion}

After Despite banking executives' current reluctance to embrace the cloud, we believe cloud computing offers banks enormous potential to not only substantially reduce the amount of money they use running on IT, but also to dramatically improve how they attract and retain customers and expand the markets they serve. Security is a major and legitimate concern. However, it is clear that cloud providers are invest in capabilities that will allow them to adhere to higher standards of security and data protection-and in the future those standards will possibly met or go beyond those held by internal operations. The important thing for bank executives to remember is that cloud computing is a journey, not a destination, and that it alone does not render sustainable competitive advantage. Like any new technology, early adopters do gain some advantage over those taking a "wait and see" attitude. But that initial advantage is fleeting, lasting only providing the rest of the pack catches up. Banks that generate lasting advantage are those that capitalize on the cloud's lower costs, unlimited capacity and flexibility to continually develop innovative products, services and channels

\section{References}

[1] Bogdan NEDELCU, Madalina-Elena STEFANET, Ioan-Florentin TAMASESCU,Smaranda-Elena TINTOIU, Alin VEZEANU, “ Cloud Computing and its Challenges and Benefits in the Bank System", Database Journal, Vol 6, January 2015.

[2] Sahil Patani, Sumesh Kadam, Prateek V. Jain, "Cloud Computing in the Banking Sector: A Survey", International Journal of Advanced Research in Computer and Communicating Engineering, Vol.3, Issue 2, February 2014.

[3] Sheel Ghule, Ms. Rupali Chikhale, Mr. Kalpesh Parmar, "Cloud Computing in Banking Services", International Journal of Scientific and Research Publications, Volume 4, Issue 6, June 20141 ISSN 2250-3153. 